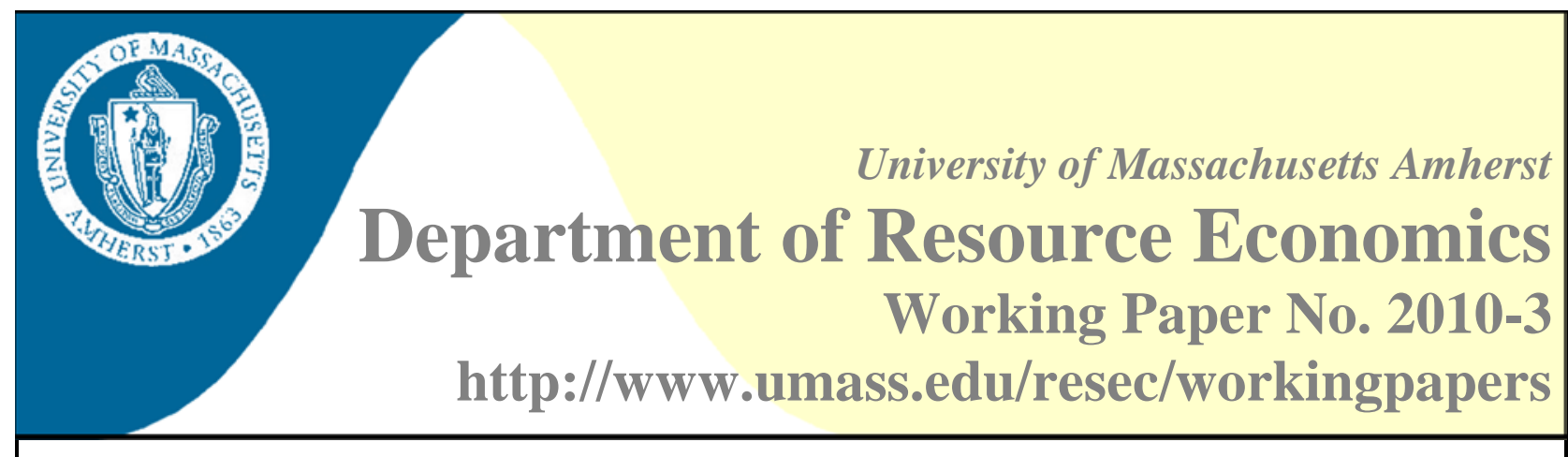

\title{
An Experimental Analysis of Compliance in Dynamic Emissions Markets
}

\author{
John K. Stranlund ${ }^{1}$, James J. Murphy ${ }^{2}$, and John M. Spraggon ${ }^{3}$
}

\begin{abstract}
:
Two important design elements for emission trading programs are whether and to what extent firms are able to bank emissions permits, and how these programs are to be enforced. In this paper we present results from laboratory emissions markets designed to investigate enforcement and compliance when these markets allow permit banking. Banking is motivated by a decrease in the aggregate permit supply in the middle of multi-period trading sessions. Consistent with theoretical insights, our experiments suggest that high permit violation penalties have little deterrence value in dynamic emissions markets, and that the main challenge of enforcing these programs is to motivate truthful self-reports of emissions.
\end{abstract}

Keywords: compliance, enforcement, emissions trading, laboratory experiments, permit markets, permit banking

JEL Classification: C91, L51, Q58

\footnotetext{
${ }^{1}$ John K. Stranlund, Department of Resource Economics

University of Massachusetts, 214 Stockbridge Hall

80 Campus Center Way, Amherst, MA 01003-9246

E: stranlund@resecon.umass.edu P: 413-545-6328 F: 413-545-5853

${ }^{2}$ James J. Murphy, Department of Economics

University of Alaska Anchorage, 201 Rasmuson Hall

3211 Providence Drive, Anchorage, AK 99508

E: murphy@uaa.alaska.edu P: 907-786-1936 F: 907-786-4115

${ }^{3}$ John M. Spraggon, Department of Resource Economics

University of Massachusetts, 212A Stockbridge Hall

80 Campus Center Way, Amherst, MA 01003-9246

E: jmspragg@resecon.umass.edu P: 413-545-6651 F: 413-545-5853
} 
August 2010

\title{
An Experimental Analysis of Compliance in Dynamic Emissions Markets
}

\author{
John K. Stranlund \\ Department of Resource Economics \\ University of Massachusetts-Amherst \\ James J. Murphy \\ Department of Economics \\ University of Alaska-Anchorage \\ John M. Spraggon \\ Department of Resource Economics \\ University of Massachusetts-Amherst
}

\begin{abstract}
Two important design elements for emission trading programs are whether and to what extent firms are able to bank emissions permits, and how these programs are to be enforced. In this paper we present results from laboratory emissions markets designed to investigate enforcement and compliance when these markets allow permit banking. Banking is motivated by a decrease in the aggregate permit supply in the middle of multi-period trading sessions. Consistent with theoretical insights, our experiments suggest that high permit violation penalties have little deterrence value in dynamic emissions markets, and that the main challenge of enforcing these programs is to motivate truthful self-reports of emissions.
\end{abstract}

Keywords: Compliance, Enforcement, Emissions trading, Laboratory experiments, Permit markets, Permit banking

JEL Codes: C91, L51, Q58

Correspondence to: John K. Stranlund, Department of Resource Economics, 214 Stockbridge Hall, University of Massachusetts-Amherst, Amherst, MA 01003, USA. Phone: (413)545-6328, Fax: (413)545-5853, E-mail: stranlund@resecon.umass.edu.

Acknowledgements: We are grateful to Tim Cason, Lata Gangadharan, and Steve Rassenti for valuable comments. Daniel Peterson and Ben Laine provided outstanding research assistance, Glenn Caffery and Emily Caffery programmed the software for this project, and Karen Pelto provided valuable administrative support. This research has been supported by a grant from the U.S. Environmental Protection Agency's National Center for Environmental Research (NCER) Science to Achieve Results (STAR) program. Although the research described in the article has been funded wholly or in part by the U.S. EPA through grant number RD-83367201-0, it has not been subjected to the EPA's peer and policy review and therefore does not necessarily reflect the views of the Agency, and no official endorsement should be inferred. 


\section{Introduction}

When developing emissions trading programs regulators must address whether and to what extent firms are able to bank emissions permits and how these programs are to be enforced. Banking allows firms to shift abatement across time in a cost-effective manner and to hedge against risk associated with uncertain abatement costs, emissions, and permit prices. Rigorous enforcement provisions are required if an emissions market is to limit aggregate emissions. In this paper we present results from laboratory experiments designed to analyze enforcement provisions and compliance behavior in emissions markets with bankable permits.

Most existing emissions trading programs allow some form of permit banking, including the EPA’s $\mathrm{SO}_{2}$ Allowance Trading program, and the European Union’s Emissions Trading Scheme (EU ETS). Most proposals for carbon trading schemes also include banking provisions. A recent example, is the American Clean Energy and Security Act of 2009 (commonly referred to as the Waxman-Markey bill after its authors), which passed the U.S. House of Representatives on June 26, 2009. ${ }^{1}$

The fundamental enforcement problem in emissions trading is to make sure that firms have enough permits to cover their emissions in each compliance period. The $\mathrm{SO}_{2}$ Allowance Trading program features emissions monitoring based on the installation of Continuous Emissions Monitoring Systems (CEMS), which provide a nearly continuous account of sources’ emissions; a financial penalty for permit violations that has usually been many times higher than going permit prices, and an offset penalty for permit violations from next-period allocations. Moreover, criminal sanctions are available for false or misleading reporting (Tietenberg 2006).

\footnotetext{
${ }^{1}$ There is significant variation in banking provisions in existing and proposed programs. The $\mathrm{SO}_{2}$ Allowance Trading program allows unrestricted saving of pollution permits for future use, but does not allow sources to borrow against future allocations. The newer generation of programs for greenhouse gas emissions tends to allow restricted permit borrowing as well, such as the EU ETS and the Waxman-Markey proposal.
} 
Greenhouse gas trading policies usually do not require the installation of CEMS (e.g., the EU ETS), so it is likely that emissions monitoring in these programs will be more uncertain than in the $\mathrm{SO}_{2}$ program. These policies do, however, included high permit violation penalties and can include very stringent sanctions for misreporting emissions, including criminal sanctions. ${ }^{2}$

Despite the importance of banking and enforcement provisions in emissions trading, little attention has been given to the relationship between these provisions. One exception is the theoretical work of Stranlund, Costello, and Chavez (2005). They argue that imperfect monitoring in trading programs with banking provisions implies that these programs must include a requirement that sources self-report their emissions. The reason is that if a firm is not monitored in a particular period, then its emissions report is the only piece of information available to a regulator to determine how many permits are to be used for current compliance purposes and how many are carried into the future. Moreover, misreporting and the failure to hold sufficient permits must be distinct violations. ${ }^{3}$ This is so because a firm that holds enough permits to cover its emissions in a period may be motivated to under-report its emissions to increase the size of its permit bank. ${ }^{4}$ In addition, Stranlund et al. argue that high permit violation penalties have little deterrence value. In fact, increasing this penalty does not reduce the amount of monitoring necessary to maintain compliance; instead it is the reporting violation penalty that

\footnotetext{
${ }^{2}$ Permit violations under the Waxman-Markey proposal would be punished with a financial penalty that is twice the value of permits during the compliance year, and an offset from the next year's allocation. In the EU ETS sanctions are left up to member states, except permit violation penalties must exceed a minimum of EUR 100/ton, which has far exceeded permit prices. Some member states can impose prison terms for both permit and reporting violations.

${ }^{3}$ Another theoretical contribution in this area is Innes (2003), but he simplifies his analysis by assuming that enforcement consists only of a certain permit violation penalty. The theoretical literature on compliance and enforcement in emissions trading using static models is extensive (including contributions by Keeler 1991, Malik 1990, 1992, and 2002, vanEgteren and Weber 1996, Stranlund and Dhanda 1999, Stranlund and Chavez 2000, Chavez and Stranlund 2003, Stranlund 2007).

${ }^{4}$ Requiring self-reporting and making misreporting a distinct violation is different from most of the economic literature on self-reporting in law enforcement. Malik (1993), Kaplow and Shavell (1994), Livernois and McKenna (1999), and Innes (1999, 2000, and 2001) all assume that self-reporting is a voluntary activity that can be encouraged by offering a lower penalty for self-reported violations.
} 
plays this role. Thus, the main enforcement challenge for emissions markets with bankable permits and imperfect monitoring is to motivate truthful emissions reporting.

We are not aware of any empirical analyses of compliance behavior in existing permit programs. However, Cason and Gangadharan (2006) examined compliance and banking behavior in laboratory emissions markets. ${ }^{5}$ Subjects in their experiments banked permits because they had only imperfect control over their emissions. They found that permit banking reduced price variability associated with stochastic emissions, but that banking led to significant noncompliance. Perhaps because they were focused on how the ability to bank permits affected compliance choices, they did not examine the distinct roles played by reporting and permit compliance in dynamic emissions markets. While they had their subjects self-report their emissions, both permit and reporting violations were punished with the same penalty. Moreover, they did not distinguish between the different violations in their data analysis.

We are also interested in the interaction between permit banking and compliance behavior, but we designed our experiments to investigate differences between reporting and permit enforcement and compliance. Permit banking in our experiments is motivated by a decrease in the aggregate permit supply in the middle of multi-period trading sessions. We conducted three treatments. Our first treatment was a simple trading experiment with banking, but without the possibility of reporting violations or permit violations. This treatment served as a baseline for our remaining experiments. Our second treatment included the reporting and permit compliance decisions, but was parameterized to induce full compliance according the model of Stranlund et al. (2005). This treatment featured imperfect monitoring, a modest reporting violation penalty, and a very low permit violation penalty. The permit violation penalty was set

\footnotetext{
${ }^{5}$ Muller and Mestelman (1998) review a number of other emission trading experiments that include banking provisions. None of them deal with the problem of noncompliance.
} 
at about $1 / 4$ of the predicted permit price. Reporting and permit compliance rates in this treatment were quite high, which supports the hypothesis that high permit violation penalties have little deterrence value in emissions markets with bankable permits.

Our third treatment cut the monitoring probability in half to investigate the consequences of weak enforcement on dynamic emissions markets. As expected, there was significant noncompliance in this treatment, but nearly all of it involved reporting violations: permit compliance in this treatment remained high. This lends further support to the notion that deterring reporting violations is the main enforcement challenge in these environments. Significant reporting violations led to increased emissions and lower permit prices, but subjects continued to bank permits to smooth the decrease in the aggregate supply of permits. Our results suggest that the main effect of weak enforcement of emissions markets with bankable permits is to produce higher emissions, but this occurs via significant reporting violations, rather than permit violations.

The rest of the paper proceeds as follows. In the next section we review the results of Stranlund et al. (2005), and specify the research questions we address with our experiments. We explain the experimental design and procedures in section 3 and present the results of the experiments in section 4 . We conclude in section 5.

\section{Theory and Research Questions}

In this section we first review the theoretical results of Stranlund, Costello, and Chavez (2005) on compliance behavior and enforcement in a dynamic emissions trading. We then use these results along with results from related studies to develop the research questions our experiments were designed to address. 


\subsection{Compliance in an emissions trading program with bankable permits}

Consider a risk-neutral firm in an emissions trading program that lasts a finite number of periods T. An exogenous number of permits are freely-allocated to the firm in each period. Each permit allows the release of one unit of emissions. Permits can be used to cover current emissions or banked for future use or sale. We do not consider borrowing against future permit allocations in our experiments. ${ }^{6}$ Let $x_{t}$ be the number of emissions permits the firm chooses to hold at the beginning of period $t$. During $t$ the firm chooses how many permits $l_{t}$ to purchase $\left(l_{t}>0\right)$ or sell $\left(l_{t}<0\right)$. Permits trade in period $t$ at a competitive price $p_{t}$. The firm also chooses emissions $e_{t}$ during period $t$. It has an abatement cost function, $c\left(e_{t}\right)$, which is strictly decreasing and convex and does not vary over the life of the program.

Because a trading program with bankable permits but imperfect emissions monitoring must include a self-reporting provision, the firm is required to submit a report $r_{t}$ of its emissions in $t$. Two types of violations are then possible. A reporting violation occurs in $t$ if the firm under-reports its emissions (i.e., $e_{t}>r_{t}$ ), and a permit violation occurs when the firm does not hold enough permits to cover its emissions (i.e., $e_{t}>\left(x_{t}+l_{t}\right)$ ).

The firm's emissions report is also its report of its compliance status and whether it is banking permits. If $r_{t}>\left(x_{t}+l_{t}\right)$, then the firm is reporting a permit violation. If $r_{t} \leq\left(x_{t}+l_{t}\right)$, then the firm is reporting that it is permit compliant and it reports that it is banking permits if $r_{t}<\left(x_{t}+\right.$ $l_{t}$ ). Reported permit violations, permit compliance, and permit banks must be distinguished from their actual values. If actual emissions exceed permit holdings, $e_{t}>\left(x_{t}+l_{t}\right)$, then there is an actual permit violation. If $e_{t}<\left(x_{t}+l_{t}\right)$ the firm has excess permits to bank, and if $e_{t} \leq\left(x_{t}+l_{t}\right)$, then the firm is permit compliant.

\footnotetext{
${ }^{6}$ Stranlund et al. allow borrowing as well as banking and, as noted in the introduction, many trading programs for $\mathrm{CO}_{2}$ emissions including borrowing provisions. Using experiments to examine compliance decisions when permit borrowing is allowed may be a worthwhile project for the future.
} 
A permit registry exists so that at any point in time the regulator has perfect information about the number of permits held by a firm, but its emissions are unknown unless the regulator audits the firm. To check for compliance in period $t$, the firm is audited with probability $\pi_{t} \in[0,1]$. An audit reveals the firm's compliance status without errors. Permit violations in period $t$ (whether they are revealed in a firm's emissions report or discovered by the authorities) are penalized at $\phi_{t}$ per unit. In addition, a one-for-one offset penalty is taken from next period's permit allocation. Reporting violations that are discovered through an audit are penalized at $\gamma_{t}$ per unit, and additional permits are surrendered to cover unreported emissions. Both $\phi_{t}$ and $\gamma_{t}$ are constants known by all parties.

Given its abatement cost function, its permit allocations, and the enforcement parameters, the firm chooses time paths for its emissions, emissions reports, and permit holdings to minimize its expected discounted abatement costs plus the value of permit transactions and potential penalties over the life of the program.

With this model, Stranlund et al. derive the firm’s compliance decision rules. Starting with the reporting decision, they show that a firm that is violating its permits truthfully reports its emissions in any $t=0, \ldots, T-1$ if

$$
\phi_{t}+\left(1-\pi_{t}\right) \beta p_{t+1}<\pi_{t}\left(\gamma_{t}+\phi_{t}\right)
$$

where $\beta$ is a constant discount factor. To interpret this condition, first note that there are two reasons a firm may choose to underreport its emissions. One is to cover up a permit violation while the other is to carry additional permits into the next period. The expected marginal penalty for a reporting violation and the undisclosed part of a permit violation is $\pi_{t}\left(\gamma_{t}+\phi_{t}\right)$. The expected marginal benefit of underreporting emissions is $\phi_{t}+\left(1-\pi_{t}\right) \beta p_{t+1}$, of which $\left(1-\pi_{t}\right) \beta p_{t+1}$ 
is the discounted expected marginal benefit of carrying additional permits into the next period, and $\phi_{t}$ is the certain per unit penalty for the part of the permit violation that the firm avoids by under-reporting its emissions.

On the other hand, if the firm is permit compliant, and perhaps has a positive permit bank, its only incentive to underreport its emissions is to increase the size of its bank. In this case, [1] is modified by eliminating the permit violation penalty. Consequently, a permit compliant firm provides a truthful emission report in $t=0, \ldots, T-1$ if

$$
\left(1-\pi_{t}\right) \beta p_{t+1}<\pi_{t} \gamma_{t} .
$$

In the last period a firm is only motivated to under-report its emissions to cover up a permit violation. Thus, a firm provides a truthful emissions report in $T$ if

$$
\phi_{T}<\pi_{T}\left(\gamma_{T}+\phi_{T}\right) .
$$

Given some $\gamma_{t}, \phi_{t}$ and $\beta p_{t+1}$ in $t=0, \ldots, T-1$, it is straightforward to demonstrate that the monitoring required to induce truthful emissions reporting is higher when the firm is violating its permits than when it is permit compliant. That is, the audit probability necessary to satisfy [1] is greater than what is necessary to satisfy [2]. However, a regulator does not know if a firm is complying with its permits unless it audits the firm, so it cannot choose a different monitoring strategy for permit compliant firms than for firms that are violating their permits. This suggests that inducing truthful reporting by all firms in all situations requires monitoring and penalties for $t=0, \ldots, T$ so that [1] and [3] are satisfied.

Now let us turn to a firm's decision to hold permits, given that it has the proper incentive to truthfully report its emissions. Stranlund et al. show that in $t=0, \ldots, T-1$, the firm holds enough permits to cover its emissions (and perhaps banks permits) if 


$$
\phi_{t}>p_{t}-\beta p_{t+1}
$$

It is common in actual and proposed trading programs to set unit permit violation penalties that are much higher than going permit prices. In contrast, [4] suggests that this penalty only needs to cover the difference between the current price and next period's discounted price in all periods but the last one. In fact, the intertemporal equilibrium in a permit market under certainty requires that real permit prices be non-increasing across time periods, and that firms will bank permits only when real permit prices are expected to remain constant (Cronshaw and Kruse 1996, Rubin 1996, Kling and Rubin 1997, Schennach 2000). This implies that the permit violation penalty has no deterrence role when firms are banking permits. In any case it should be possible to maintain compliance in a trading program with bankable permits with permit violation penalties that are far lower than going permit prices.

In the last period of a trading program the firm is permit compliant if

$$
\phi_{T}>p_{T}
$$

The permit violation penalty needs to cover the permit price in the last period because no offset penalty is available.

From the compliance incentives [1] though [5], it is easy to see that the permit violation penalty in emissions trading programs with bankable permits need not be very high at all. In fact, even though we often think that we can conserve monitoring effort by increasing penalties, we cannot do so with a permit violation penalty in this context. We can, however, reduce monitoring costs by increasing the reporting violation penalty. ${ }^{7}$ Thus, deterring permit violations is not the most important aspect of enforcing emissions markets with bankable permits. Instead,

\footnotetext{
${ }^{7}$ To see this use [1] and [3] to calculate the minimum audit probability at which the firm will provide a truthful emissions report in every period. Note that these audit probabilities are increasing in the permit violation penalty, but decreasing in the reporting violation penalty.
} 
enforcement of an emissions trading program with a banking provision and imperfect monitoring should focus primarily on inducing truthful emissions reporting.

To conclude this section let us consider a firm's emissions decision. Assuming that it is violating it permits and misreporting its emissions in $t=0, \ldots, T-1$, its interior choice of emissions satisfies:

$$
-c^{\prime}\left(e_{t}\right)=\pi_{t}\left(\gamma_{t}+\phi_{t}+\beta p_{t+1}\right)
$$

That is, the firm chooses its emissions so that its marginal abatement cost is equal to the expected sum of the unit reporting and permit violation penalties, as well as the discounted value of the unit offset penalty If the firm is permit compliant (perhaps it is banking permits) then [6] is modified by setting $\phi_{t}=0$ so that we have $-c^{\prime}\left(e_{t}\right)=\pi_{t}\left(\gamma_{t}+\beta p_{t+1}\right)$. Regardless of whether the firm is violating its permits, if it is reporting its emissions truthfully then its choice of emissions in $t=0, \ldots, T-1$ is determined by $-c^{\prime}\left(e_{t}\right)=\beta p_{t+1}$. In the last period $T$, the firm chooses its emissions so that $c\left(e_{T}\right)+\pi_{T}\left(\gamma_{T}+\phi_{T}\right)=0$ if it is violating its permits and misreporting to cover up part of the permit violation. If the firm is permit compliant in the last period it chooses its emissions so that $c\left(e_{T}\right)+p_{T}=0$.

\subsection{Research questions}

The results presented above and previous work on compliance in emissions trading lead us to several research questions that we address with laboratory experiments. In these experiments we generate a strong incentive to bank permits by reducing the aggregate supply of permits in the middle of each multi-period trading session. Firms have an incentive to save permits in early time periods to smooth the drop in the permit supply in later periods. 
Given the tendency to set high permit violation penalties in real emissions trading programs and the contrary theoretical suggestion that high permit violation penalties are not very useful deterrents, it is important to address the following question:

Research Question 1. Can reporting and permit compliance in an emissions market with bankable permits be achieved with imperfect monitoring and reasonable reporting violation penalties, but permit violation penalties that are far lower than expected permit prices?

Since imperfect emissions monitoring in a dynamic trading program requires firm selfreports, and firms can commit both reporting violations and permits violations, an obvious first question to ask about weak enforcement of dynamic emissions markets is the following:

Research Question 2. How is noncompliance manifested under a weakly enforced emissions market with bankable permits? Is it mainly in reporting violations, permit violations, or some combination of the two?

If weak enforcement produces mainly reporting violations, this reinforces the theoretical result that the main enforcement challenge in these settings is making sure that firms have the correct incentive to report their true emissions. If weak enforcement produces significant permit violations, then the theoretical insight may not be correct. Moreover, significant permit violations would imply that the violation incentive overwhelms the incentive to bank permits.

Regardless of how noncompliance is manifested, if it is significant then it will impact that evolution of permit markets. Hence, our experiments address: 
Research Question 3. What are the effects of weak enforcement on the paths of aggregate emissions, permit prices, and aggregate permit banking?

Of course the ultimate goal of both reporting and permit violations is to pollute beyond permitted levels, either now or in the future. Thus, significant undetected reporting and permit violations will lead to higher aggregate emissions over the life of an emission trading regulation, which, in turn, should lead to lower permit prices. The effect on banking is not as clear. It is possible that significant noncompliance could undermine firms' incentives to save permits, but it is also possible that emissions markets retain the ability to allocate permits over time despite weak enforcement.

Our next research questions address issues related to individual decisions in dynamic emissions markets. A unique feature of permit markets is that changes in enforcement parameters can have direct effects on firms' decisions, as well as indirect effects that work through changes in permit prices. Stranlund and Dhanda (1999) show theoretically that increased enforcement (either increased monitoring or permit violation penalties) in a static environment with widespread permit violations has a negative direct effect on violations but a weaker positive indirect effect because increased enforcement leads to higher permit prices. They also show that there is no direct effect of enforcement on emissions, there is only a negative price effect. Murphy and Stranlund (2006) examined these direct and indirect price effects in their experimental analysis of static emissions markets without emissions self-reporting, and found strong support for the theory. We are interested in whether these hypotheses are supported in a more complex dynamic environment. Hence, we ask: 
Research Question 4. What are the direct and indirect price effects of changes in enforcement on firms' emissions and compliance choices?

Stranlund and Dhanda (1999) also argue that individual violations in emission markets are independent of firm-level characteristics, like their marginal abatement costs or permit allocations. We expect this independence result to also hold in a dynamic environment. Consider the compliance decisions rules [1] through [5] above. Note that all of these conditions depend only on permit prices and enforcement parameters. Since they are independent of firm-level characteristics, firms' reporting and permit violation choices should be independent of these characteristics as well. Thus, we designed our experiments to address the following:

Research Question 5. What are the effects of differences in firms' payoff functions and permit allocations on their emissions and compliance choices?

This independence result is important for designing enforcement strategies for emissions markets, because it implies that a regulator cannot use differences among firms to target its enforcement effort. Murphy’s and Stranlund's (2007) experiments on static laboratory emissions markets support the hypothesis that firms' permit violations are independent of their abatement costs. They do find, however, some evidence that violations may depend in part on initial permit allocations, because these allocations determine which firms will buy permits and which will sell permits. Nevertheless, they demonstrate that the marginal productivity of enforcement resources 
does not depend on firm-level characteristics, suggesting that these characteristics cannot be used by regulators who wish to design enforcement to limit aggregate noncompliance.

\section{Experimental Design and Procedures}

\subsection{Experimental Design}

Our experiments were designed to address the five research questions above. We framed the experiments as a production decision in which permits conveyed a right to produce one unit of a fictitious good to avoid introducing potential biases due to individual attitudes about the environment or emissions trading. Each session was organized into three separate but identical six-period stages, similar to the approach used by Anderson and Sutinen (2006) in their study of trading in fishery quota markets. This provided subjects with an opportunity to gain experience with the dynamic environment, adapt, and repeat.

In each period subjects simultaneously produced units of the good and traded in a continuous double auction for permits. The eight subjects in a group were evenly divided into one of four subject types. The distinguishing characteristics of the subject types were their marginal earnings from production and their initial permit allocations in Tables 1 and 2. These production earnings and permit allocations were the same for all periods in all sessions. We induced permit banking by reducing the aggregate supply of permits from 68 in the first three periods of a stage to 16 in the last three periods.

At the end of each period, subjects were required to report that period's production. After all reports were submitted, production choices were audited with a known probability. Permit violations that were either voluntarily self-reported or uncovered through an audit were punished with a constant per-unit financial penalty. In addition, a subject's permit shortfall in any period 
but the last was offset by a one-for-one reduction in the subject's initial allocation of permits in the next period. If the permit shortfall exceeded the subject's initial endowment in the next period, then the subject was declared bankrupt and was not allowed to participate in the remainder of the stage. If an audit revealed a reporting violation, then the subject was assessed a reporting penalty that differed from the permit shortfall penalty and the permits required to cover the reporting violation were collected. After the audits, unused permits were banked. The perfect foresight, perfect compliance equilibrium in this environment consists of 42 units of total production and an equilibrium permit price of about $\$ 79$ in each period.

\subsection{Treatments}

Our experimental design consists of three treatments that differed according to enforcement aspects. All other factors were the same across treatments.

Strong Enforcement: This treatment was designed to induce full compliance using an enforcement strategy derived from equations [1] through [5]. We decided to slightly overenforce by using an audit probability of $\pi_{t}=0.7, t=1,2, \ldots, 6$, and assessing permit and reporting violation penalties that were about $\$ 20$ higher than needed to satisfy [1] through [5]. Since our perfect foresight, perfect compliance equilibrium produces the permit price $p_{t}=\$ 79$ for each $t=1,2, \ldots, 6,[4]$ and [5] suggest that the permit shortfall penalty can be set to zero for periods 1 through 5 and $\$ 79$ for period six. Therefore, we chose $\phi_{t}=\$ 20$ for $t=1, \ldots, 5$, and $\phi_{6}=\$ 100$.

For the reporting penalty in $t=1,2, \ldots, 5,[1]$ implies that $\gamma_{t}$ needs to be set so that $\gamma_{t}>\left(1-\pi_{t}\right)\left(\phi_{t}+p_{t+1}\right) / \pi_{t}$ to induce truthful reporting. (There is no discounting in a short 
experiments with known end dates so $\beta=1$ ). If $\pi_{t}=0.7, \phi_{t}=\$ 20$, and $p_{t+1}=\$ 79$, then $\gamma_{t}>\$ 42.43$. Setting this penalty about $\$ 20$ higher yields $\gamma_{t}=\$ 60, t=1,2, \ldots, 5$. We set $\gamma_{6}=\$ 60$ in the last period as well, because from [3], $\gamma_{6}=\$ 60$ and $\phi_{6}=\$ 100$ imply that a monitoring probability of at least 0.625 should be sufficient to induce truthful reporting in the last period.

The Strong Enforcement treatment was designed to address Research Question 1. Note that we set the permit violation penalty at about $1 / 4$ of the predicted permit price for all periods but the last. Note as well that the theoretical model allows us to set the reporting violation penalty below the predicted permit price. Despite random monitoring, a modest reporting violation penalty and a very low permit violation penalty, we expect very high rates of compliance in this treatment.

Weak Enforcement: This treatment is the same as the Strong Enforcement treatment except that the monitoring probability was reduced by half to $\pi_{t}=0.35, t=1, \ldots, 6$. This should lead to significant noncompliance. This treatment allows us to address Research Questions 2 through 5. With respect to Research Question 5, we did not attempt to separate the effects of differences in individuals’ permit allocations from differences in their marginal production earnings on their production and violation choices. Therefore, this question is more specifically about the effects of the combination of subject-type characteristics on their production and violation choices.

Forced Compliance: In this treatment, it was not possible for subjects to violate their permits or submit false production reports. Since the Strong Enforcement treatment was designed to induce full compliance, the outcomes in the Forced Compliance and Strong Enforcement treatments should be identical. We included the Forced Compliance treatment to determine if 
allowing subjects to violate their permits or misreport their production changed their behavior, even though there was no incentive for them to do so.

\subsection{Experiment procedures}

A total of 72 participants were recruited from the general student population at the University of Massachusetts, Amherst. Subjects were told that to be eligible they had to participate in four two-hour sessions (two days a week for two consecutive weeks). Subjects were paid \$5 for agreeing to participate and showing up on time for the first session and were then given an opportunity to earn additional money in each experiment. Subjects earned experimental dollars (E\$) that were converted to US dollars at a pre-announced exchange rate. Subjects were paid in cash at the end of the final session. Average earnings per session ranged between $\$ 14.69$ and $\$ 33.22$, with a mean of $\$ 25.00(\sigma=3.15)$.

Subjects were recruited into one of three separate 24-person cohorts (labeled I-III in Table 3). The composition of the 24-person cohort was the same in all four two-hour sessions. Before the start of each session, the cohort was randomly sub-divided into three eight-person groups. Hence, group composition was constant for all three stages within the session, but varied across sessions. The experiments were conducted in a computer lab at the University of Massachusetts-Amherst using software designed in Visual Basic specifically for this research. To familiarize subjects with the experiments, the first of the four sessions was for training purposes. During the trainer, subjects first read the online instructions, which included interactive questions to ensure that they understood the instructions before proceeding. ${ }^{8}$ They then participated in a two-stage practice experiment. The first stage of the practice experiment

\footnotetext{
${ }^{8}$ The experiment instructions are available upon request.
} 
followed the same rules as the Forced Compliance treatment (but with different parameters), and the second stage followed the rules of the Strong Enforcement treatment (again with different parameters). The data from the trainers were not included in the analysis.

After the training session on the first day, each cohort participated in three real-data sessions, labeled sessions 1, 2, or 3 in Table 3. Each of the three 24-person cohorts participated in all three treatments, one treatment for each session. The sequence of treatments across sessions varied among cohorts as shown in Table 3. For example, all three eight-person groups within Cohort I participated in three separate but identical six-period stages of the Weak Enforcement treatment in their first real data session.

The experiments were designed for a total of 27 stages per treatment (three cohorts $\times$ three groups within a cohort $\times$ three stages per group within a session). After dropping stages in which there were bankruptcies or computer problems, the results discussed in the next section include 23 completed stages in the Forced Compliance treatment and 25 in both the Strong Enforcement and Weak Enforcement treatments. Table 4 provides the details of how many group-level observations we have for each stage and treatment

Subjects produced each unit of the good sequentially by clicking on a button that initiated the production process. Production of a single unit took 10 seconds. After production of the unit was completed the "Earnings from Production” were immediately added to the individual's cash balance. Subjects were able to "plan" future production within the period by indicating the total number of units to produce. Once production of a unit was completed, if there were any "planned" units, the 10-second production process for the next began automatically. Subjects could increase or decrease their "planned" production, but units that were "in progress" or “completed" were committed and could not be changed. 
During a market period, subjects could alter their permit holdings by trading in a continuous double auction. In the permit market, individuals could submit bids to buy or asks to sell a single permit (provided that they had a permit available to sell). The highest bid and lowest ask price were displayed on the subjects' computer screens. A trade occurred whenever a buyer accepted the current ask or a seller accepted the current bid. After each trade, the current bid and ask were cleared and the market opened for a new set of bids and asks. The trading price history was displayed on the subjects’ screens.

Each period lasted a total of four minutes. The permit market was open for the entire period, but production had to be completed in three minutes, which was more than sufficient for each subject to produce up to their capacity constraint. We provided the additional minute of permit trading to give subjects a final opportunity to adjust their permit holdings. (Such a reconciliation period is common in emissions markets). The computer screen displayed the time remaining for both the production and the permit markets.

Since it was possible for individuals to lose money either through permit trading or penalties, we implemented two bankruptcy rules. First, if a subject’s cash balance ever fell below negative $\mathrm{E} \$ 800$, he or she was declared bankrupt and no longer allowed to participate in the current stage. Second, a subject was also considered bankrupt if the offset penalty for reported and uncovered permit violations exceeded his or her permit allocation in the next period. $^{9}$

To help subjects understand how to allocate their permits across time periods, in all treatments the instructions explained that the best way to use their permits was to spread them out evenly over time. In addition, the software included an "even use” calculator that indicated

\footnotetext{
${ }^{9}$ We also instituted a price ceiling of $\mathrm{E} \$ 400$ above which offers to trade permits were not allowed. This ceiling is well above the highest possible marginal production benefit (i.e., E\$161) and was never reached.
} 
how to smooth production in the remaining periods based on the current permit bank plus all future permit allocations. The calculator did not reveal optimal production or permit trading behavior. This is like the planner used by Godby et al. (1997). At the end of each period, subjects were given a summary of their production earnings, revenue or expenditures from permit trades, any penalties for the period, and a running tally of their cumulative cash balance.

\section{Results}

In this section we present the results of our experiments. We begin with an examination of aggregate-level outcomes before proceeding to individual production and compliance choices.

\subsection{Aggregate compliance}

Aggregate permit and reporting violations in the Strong Enforcement and Weak Enforcement treatments are summarized in Table 5. Since the Strong Enforcement treatment was parameterized to induce perfect compliance, permit and reporting violations were infrequent. Subjects complied with their permits about $96 \%$ of the time, and half of the permit violations were only one-unit violations. This suggests that some subjects "tried out" permit violations from time to time, but they were not motivated to violate their permits systematically. There were more reporting violations (8.25\%) than permit violations (4.08\%), but again roughly half of the reporting violations were one-unit violations. Hence, in response to Research Question 1, these results suggest that high rates of compliance can be achieved in emissions trading programs with permit banking despite imperfect monitoring, low permit violation penalties, and modest reporting violation penalties. 
As expected, there were significantly more reporting violations in the Weak Enforcement treatment. ${ }^{10}$ Note, however, that permit compliance remained quite high, with one-unit violations making up about half the permit violations. ${ }^{11}$ We will see shortly that there was a significant amount of banking in the Weak Enforcement treatment, and infrequent permit violations are consistent with significant permit banking. However, about $27.4 \%$ of reporting choices under the Weak Enforcement treatment were violations, two-thirds of which were violations of 2 units or more. With regard to our Research Question 2, the main effect of weak enforcement is to encourage substantial reporting violations rather than permit violations.

\subsection{Aggregate Production}

Since the Strong Enforcement treatment was designed to produce high rates of compliance, and largely did so, we should not observe systematic differences in aggregate production between the Strong Enforcement and Forced Compliance treatments. However, significant reporting violations in the Weak Enforcement treatment should lead to an increase in aggregate production as these reporting violations are associated with random additions to permit banks because of imperfect auditing. Figure 1 presents a plot of the mean aggregate production over time by treatment for sessions 2-3 and stages 2-3. Consistent with expectations, average aggregate production is highest in the Weak Enforcement treatment; the plots for the other two treatments appear to be similar.

\footnotetext{
${ }^{10}$ Result from Fisher exact tests. $\mathrm{H}_{0}$ : reporting violation rates with Strong Enforcement = reporting violation rates with Weak Enforcement is rejected ( $\mathrm{p}=0.00$ ).

${ }^{11}$ There is a small, but statistically significant, difference in permit compliance rates between the Strong and Weak Enforcement treatments. With both permit compliance rates above $90 \%$, the differences are not economically significant. Results from Fisher exact test. $\mathrm{H}_{0}$ : permit violation rates with Strong Enforcement $=$ permit violation rates with Weak Enforcement is rejected $(\mathrm{p}=0.00)$.
} 
To test for treatment effects on aggregate production, Table 6 presents the results of two linear random effects models of the general form $y_{g t}=\alpha_{0}+x_{g t} \beta+v_{g}+\varepsilon_{g t}$. Group-level random effects are $v_{g} \sim N\left(0, \sigma_{v}^{2}\right), \varepsilon_{g t} \sim N\left(0, \sigma_{\varepsilon}^{2}\right)$ is the idiosyncratic error term, and $x_{g t}$ is a vector of independent variables (including interaction terms) for group $g$ in period $t=1, \ldots, 6$. The dependent variable, $y_{g t}$, in Table 6 is aggregate production. WeakEnforcement and StrongEnforcement are dummy variables for these treatments; Period is $t=1, \ldots, 6$ in each stage, and Period $^{2}$ is included to capture potential nonlinear time trends in aggregate production. Possible learning effects can be manifested in two ways. Recall that after a 2-hour training session, all subjects participated in a series of three real data sessions with a different treatment in each session (see Table 3). The dummy variable Session 1 reflects the decisions made by "inexperienced" subjects. The other potential source of learning is through repetition of the same treatment within a particular session in a series of three identical 6-period stages. The first model in Table 6 includes data from all three stages, and the second includes just stages 2 and 3. Unless otherwise noted, our discussion focuses on the results from stages 2 and 3 within sessions 2 and 3 because these subjects have the most experience. The constant in the Table 6 regressions is interpreted as the aggregate production in the Forced Compliance treatment in stages 2-3 of sessions 2-3 in period 0 .

As expected there is no statistically significant difference in aggregate production between the Forced Compliance and Strong Enforcement treatments. It is interesting that both series have a concave shape in these treatments; production tends to start out low, increases to a maximum in the middle of a stage, and then decreases. More importantly, production is significantly higher under Weak Enforcement in every period, and the effect is larger in sessions 2 and 3, stages 2 and 3. This addresses the first part of our Research Question 3. Higher 
production due to weak enforcement is not surprising, but two elements of this finding are new with this study. First, when there is significant motivation to bank permits, the pathway from weak enforcement to higher aggregate emissions is through significant reporting violations, rather than permit violations (see Table 5). Second, it is clear that weak enforcement does not undermine the value of banking to smooth production over time. Recall that the aggregate permit supply was 68 per period in periods 1-3, and reduced to 16 per period in periods 4-6. Figure 1 does not show the steep drop in production in the later periods that would occur if subjects failed to bank permits effectively.

\subsection{Banking}

In anticipation of the sharp decline in the aggregate permit supply in periods 4-6, to smooth production permits should be banked in the first three periods and then withdrawn in the last three. This is precisely the pattern we observe in Figure 2 which shows the mean quantity of permits banked over time for each treatment in sessions 2 and 3, stages 2 and 3. It is clear from Figure 2 that aggregate banking was no different under the Forced Compliance and Strong Enforcement treatment (in fact, the Forced Compliance and Strong Enforcement banking series are almost indiscernible). Banking under the Weak Enforcement treatment follows essentially the same pattern as for the other treatments, but the quantity banked tended to be somewhat higher in each period. This separation disappears when we consider mean quantity of permits banked from all stages and sessions.

Table 7 presents the results from two linear random effects models of aggregate banking. The framework is similar to the model presented in Table 6, with two exceptions. The first, of course, is the dependent variable, $y_{g t}$, in Table 7 is the aggregate quantity of permits banked by 
group $g$ in period $t$. Second, the period variables are defined differently. Figure 2 shows the permit bank growing linearly for the first three periods, then sharply reversing course in the last three periods. For the period variable, we constructed a linear spline with a knot at period four. The variable Periods 1-3 equals the period number for the first three periods and equals three for the last three periods. The variable Periods4-6 equals zero for the first three periods and equals period number minus three for the last three periods. Note that this implies Periods 1-3 plus Periods4-6 equals the period number. As in Table 6, the first model includes data from all three stages, while the second model includes stages 2 and 3 only.

Focusing on the results for stages 2 and 3, we can see that the permit bank grows by about 25 permits per period in the first three periods, and is then drawn down at a roughly comparable rate, about 27 permits per period in the last three periods. This pattern of banking over time is constant across all three treatments. As expected, there are no statistically significant differences in the size of the aggregate permit banks in the Forced Compliance and Strong Enforcement treatments; however, Weak Enforcement does have a positive and significant effect on banking levels. With regard to Research Question 3, the most important lesson here is that, despite strong incentives to be noncompliant under the Weak Enforcement treatment, individuals still used the banking provision to build up their banks in early periods to smooth the drop in the aggregate supply of permits in later periods. Thus, weak enforcement need not prevent pollution sources from allocating production through time in a reasonably efficient way. 


\subsection{Permit prices}

Significant reporting violations, higher production, and banking under the Weak Enforcement treatment should be reflected in lower permit prices. Figure 3 presents a plot of the mean permit prices over time by treatment, and as expected, Forced Compliance and Strong Enforcement follow similar paths, and Weak Enforcement has the lowest prices. More formally, Table 8 presents the results of two linear random effects models of permit prices using individual trade data. The models follow the basic structure as those in Table 6, with the exception of the change in the dependent variable.

As expected, permit prices are significantly lower under the Weak Enforcement treatment than under the other two treatments. The separation between the Weak Enforcement price series and the series for other two treatments is not as pronounced when all sessions and stages are considered, but the differences are still significant. This answers the final part of Research Question 3. There are significant differences in elements of the price series between the Forced Compliance and Strong Enforcement treatments, but these are not systematic.

The price levels under the Weak Enforcement treatment suggest that subjects were more compliant than theory would predict, even though we observe significant reporting violations in this treatment. Recall that a permit compliant firm provides a truthful report in any $t=0, \ldots, T-1$ if and only if $\pi_{t} \gamma_{t} \geq\left(1-\pi_{t}\right) \beta p_{t+1}$. In our experiments the discount factor is $\beta=1$. Under the Weak Enforcement treatment $\pi_{t} \gamma_{t}=(.35)(42.43)=14.85$ is the expected marginal cost of misreporting production. Average prices were around \$70 in the second and third sessions and stages of the Weak Enforcement treatment; therefore, the expected marginal benefit of misreporting is about $\left(1-\pi_{t}\right) p_{t+1}=(.65)(70)=45.5$, which is more than triple the expected marginal cost. Thus, theory would have predicted a combination of higher reporting violations 
and lower permit prices than we observe. In response to the price part of Research Question 3, weak enforcement leads to lower permit prices, but perhaps not as low as one would expect.

\subsection{Individual production and compliance choices}

We now turn to an analysis of individual behavior in our experiments. Table 9 contains results of three linear random effects models of individual production decisions, one for each stage. The models are of the general form $y_{i t}=\alpha_{0}+x_{i t} \beta+v_{i}+\varepsilon_{i t}$. Individual subject random effects are $v_{i} \sim$

$N\left(0, \sigma_{v}^{2}\right), \varepsilon_{i t} \sim N\left(0, \sigma_{\varepsilon}^{2}\right)$ is the idiosyncratic error term, and $x_{i t}$ is a vector of independent variables (including interaction terms) for subject $i$ in period $t=1, \ldots, 6$. AveragePrice is the mean of all trades that occurred in a period for a particular group. SubjectTypeB, SubjectTypeC, and SubjectTypeD are dummy variables for the subject types identified in Tables 1 and 2. We have defined all the other variables in these regressions already. Similar regressions were run with session dummies and AveragePrice interacted with ForcedCompliance and WeakEnforcement; none of these effects were significant, so we dropped them to facilitate interpretation of the results. The constant in these regressions refers to subject type A's production under the Strong Enforcement treatment in period zero.

Table 10 presents the results from three random effects logit models that estimate the probability of an individual reporting violation, by stage, for the Weak Enforcement and Strong Enforcement treatments. We choose to focus on the probability of misreporting, rather than the size of reporting violations, because of the high compliance rates and the fact that violators tended to misreport production by small amounts. Moreover, we did not analyze individual permit violation decisions because these were so infrequent in the Strong Enforcement and Weak Enforcement treatments. 
The results in Table 9 indicate that changes in permit prices produced a negative effect on production, as expected, and this effect appears to be similar across treatments and across stages. More interesting is how weak enforcement affects individual production levels. In their experimental study of emissions trading without banking, Murphy and Stranlund (2006) found that there was no direct effect of enforcement on production decisions; rather changes in production arise indirectly through changes in permit prices. Recall that this motivated part of our Research Question 4. However, the results in Table 9 indicate that weak enforcement had a significant positive direct effect on the production choices of most subjects in stages 2 and 3 of our experiments. ${ }^{12}$ In addition, the indirect price effect is significant but tends to be smaller than the direct effect. In stages 2 and 3, every experimental dollar decline in average permit price due to weak enforcement had a -0.07 unit effect on individual levels of production. Since average permit prices for sessions 2-3, stages 2-3 of the Weak Enforcement treatment were about $\$ 5-\$ 10$ less than under the Strong Enforcement treatment (refer to Figure 3), the indirect price effect of lower enforcement on individual production in stage 3 is about 0.35 to 0.70 more units of production per individual and per round.

It is unclear why the direct effect of weaker enforcement on individual production is not zero, and in fact, is much larger than the indirect effect through changes in permit prices for most subjects. It is quite possible that the permit price is simply not a strong signal of compliance incentives in these experiments. Recall that subjects were more compliant (in terms of production reporting) than theory would predict. This could mean that the behavioral incentives

\footnotetext{
${ }^{12}$ For example, in stage 3 the direct effects of weak enforcement by subject type are: for subject type A, WeakEnforcement $=1.74(\mathrm{p}=0.00)$; for subject type B, WeakEnforcement + WeakEnforcement $\times$ SubjectTypeB $=$ 0.21 ( $\mathrm{p}=0.67)$; for subject type C, WeakEnforcement + WeakEnforcement $\times$ SubjectTypeC $=0.97(\mathrm{p}=0.05)$, and for subject type D, WeakEnforcement + WeakEnforcement $\times$ SubjectTypeD $=1.73(\mathrm{p}=0.00)$. (Preceding tests are Wald chi-squared tests for the null hypothesis that the direct effect values are equal to zero). Thus, in stage 3 the direct effect of weak enforcement is positive and significant for all subject types except subject type B.
} 
of the Weak Enforcement treatment were not fully incorporated in the permit price. It is plausible that because permit prices were a weak and indirect signal of the value of production rights, the clear enforcement strategy of the Weak Enforcement treatment became a stronger motivator.

This reasoning is consistent with our results concerning the impact of enforcement and prices on the likelihood of individual reporting violations in Table 10. As expected the direct effect of weak enforcement is strongly positive. However, the effect of permit price on the decision to misreport production is small, and only significant in stage 2. By contrast, Murphy and Stranlund (2006 and 2007) and Cason and Gangadharan (2006) found significantly negative impacts of permit prices on compliance.

To complete this section, let us answer Research Question 5 by turning to subject type effects on individual production and compliance decisions. Recall that we expect significantly different production levels among subject types because of differences in the marginal production earnings. The results in Table 9 are consistent with this expectation. More specifically, since subject types A and B have higher marginal production benefit functions than types C and D (Table 1), their production levels should be significantly higher. ${ }^{13}$

In contrast, we expect there to be no significant subject type effects on compliance decisions, because conceptually these decisions are based on comparisons of permit prices and expected penalties, none of which vary with marginal production benefits. Table 10 clearly indicates that differences in subject types have no effect on individual decisions to misreport their production (none of the subject type coefficients are significant).

\footnotetext{
${ }^{13}$ As expected, for each treatment, a joint test of the hypothesis that production choices are the same among all firm types is rejected ( $\mathrm{p}=0.00$ for each of the three treatments).
} 


\section{Summary and policy implications}

Our results have several implications for the design and performance of emissions markets that include bankable permits. Our most important contribution is to provide support to the theoretical conclusion that the most challenging part of enforcing dynamic emissions markets is to motivate truthful emissions reporting. Our results suggest that it is possible to achieve high rates of reporting and permit compliance in trading programs with imperfect emissions monitoring, a reporting penalty that is less than expected and observed permit prices, and a very low permit violation penalty. It is common in existing and proposed trading programs to set permit violation penalties that exceed expected and realized permit prices. Theory and our experimental evidence suggest that these high penalties serve little purpose. Moreover, weak enforcement is manifested in significant reporting violations, not permit violations. This adds additional support for the notion that the main task of enforcement in dynamic emissions markets is to promote truthful self-reporting. This insight is particularly relevant for the newest generation of trading programs for greenhouse gas emissions that will not be able to rely on continuous emissions monitoring technologies.

While weak enforcement and significant misreporting led to higher emissions and lower permit prices in our experiments, observed prices suggest that subjects did not misreport as much as a theory would predict. The expected marginal benefits of misreporting were significantly higher (about three times higher) than the expected marginal costs of misreporting. Moreover, despite weak enforcement and significant reporting violations, the permit market continued to function; in particular, subjects were able to allocate emissions through time reasonably well. This may suggest that weak enforcement may not as costly as one would predict with a standard model of expected-payoff maximizing firms. 
We have also contributed to existing experimental evidence of the determinants of individual emissions and compliance decisions in emissions markets. Previous theoretical and experimental work on static emissions markets suggests that there is no direct effect of enforcement changes on the emissions choices of firms, only a negative indirect effect because stricter enforcement leads to higher permit prices. The results from our dynamic environment suggest a different conclusion; we found a significant direct effect of enforcement on individual emissions for some subject types. More research is needed to fully understand the role of enforcement on firm's emissions when permits can be banked.

Finally, previous work with static models and experiments show that the characteristics of firms, such as their marginal abatement costs and their permit allocations, cannot be used by regulators who wish to allocate enforcement resources to minimize noncompliance. We have shown that this conclusion holds in a dynamic setting as well—-there were no subject type effects on individual decisions to misreport in our experiments. The practical implication of this result is that regulators do not need information about how individual firms are different from each other to set enforcement strategies to reach particular compliance goals.

There are many ways that this research can be extended, and we have already mentioned a few. Let us note one more that we think is particularly important. Perhaps the most difficult aspect of designing greenhouse gas trading policies is how to handle the severe uncertainty in abatement costs and benefits. Recent analyses and policy proposals have focused on permit price controls in addition to banking provisions to limit uncertainty in emissions markets. However, to our knowledge there is no trading program that combines price controls and permit banking, so we cannot look to field experience to understand how these two provisions work together. It is also not clear what role price controls play in modifying firms' compliance 
incentives. Well-designed laboratory experiments could provide useful information about how permit banking, permit price controls, and enforcement strategies can be combined in emissions markets. 
Table 1. Marginal Earnings from Production

\begin{tabular}{ccccc}
\hline & \multicolumn{4}{c}{ Subject Type } \\
\cline { 2 - 5 } $\begin{array}{c}\text { Number } \\
\text { of Units } \\
\text { Produced }\end{array}$ & A & B & C & D \\
\hline 1 & 161 & 151 & 129 & 125 \\
2 & 145 & 134 & 113 & 105 \\
3 & 130 & 119 & 98 & 88 \\
4 & 116 & 106 & 84 & 74 \\
5 & 103 & 95 & 73 & 63 \\
6 & 91 & 86 & 63 & 54 \\
7 & 80 & 79 & 53 & 47 \\
8 & 70 & 74 & 44 & 42 \\
9 & 61 & 70 & 35 & 38 \\
10 & 53 & 67 & 27 & 35 \\
11 & 45 & 59 & 19 & 27 \\
12 & 37 & 51 & 11 & 19 \\
\hline
\end{tabular}

In each 8-person group, there were two subjects of each type.

Table 2. Initial Permit Allocations

\begin{tabular}{cccccc}
\hline & \multicolumn{5}{c}{ Subject Type } \\
\cline { 2 - 5 } Period & A & B & C & D & $\begin{array}{c}\text { Total } \\
\text { Permit } \\
\text { Supply }\end{array}$ \\
\hline $1-3$ & 5 & 5 & 12 & 12 & 68 \\
$4-6$ & 1 & 1 & 3 & 3 & 16 \\
\hline In each 8-person group, there were two subjects of each type.
\end{tabular}


Table 3. Sequence of Treatments

\begin{tabular}{clll}
\hline Cohort & Session 1 & Session 2 & Session 3 \\
\hline \multirow{2}{*}{ I } & Weak & Forced & Strong \\
& Enforcement & Compliance & Enforcement \\
\multirow{2}{*}{ II } & Forced & Strong & Weak \\
& Compliance & Enforcement & Enforcement \\
III & Strong & Weak & Forced \\
& Enforcement & Enforcement & Compliance
\end{tabular}

Each cohort consists of 24 subjects. At the start of each session, each cohort was sub-divided into three eight-person groups.

Table 4. Number of Groups in Each Stage and Treatment

\begin{tabular}{lcccc}
\hline \multicolumn{1}{c}{ Treatment } & Stage 1 & Stage 2 & Stage 3 & Total \\
\hline Forced Compliance & 8 & 7 & 8 & 23 \\
Strong Enforcement & 8 & 8 & 9 & 25 \\
Weak Enforcement & 7 & 9 & 9 & 25 \\
\hline
\end{tabular}

Each cell contains the number of eight-person groups. 
Table 5. Permit and Reporting Violations by Treatment

\begin{tabular}{|c|c|c|c|c|}
\hline \multirow[b]{3}{*}{$\begin{array}{c}\text { Violation } \\
\text { level }\end{array}$} & \multicolumn{4}{|c|}{ Percent of Observations } \\
\hline & \multicolumn{2}{|c|}{ Strong Enforcement } & \multicolumn{2}{|c|}{ Weak Enforcement } \\
\hline & Permit & Reporting & Permit & Reporting \\
\hline 0 & $95.92 \%$ & $91.75 \%$ & $91.58 \%$ & $72.58 \%$ \\
\hline 1 & $2.08 \%$ & $4.50 \%$ & $4.17 \%$ & $9.17 \%$ \\
\hline 2 & $0.83 \%$ & $1.75 \%$ & $1.50 \%$ & $6.50 \%$ \\
\hline 3 & $0.42 \%$ & $0.50 \%$ & $0.92 \%$ & $4.67 \%$ \\
\hline $4+$ & $0.75 \%$ & $1.50 \%$ & $1.84 \%$ & $7.08 \%$ \\
\hline
\end{tabular}

Table 6. Linear random effects model of aggregate production

\begin{tabular}{|c|c|c|c|c|}
\hline \multirow[b]{2}{*}{ VARIABLES } & \multicolumn{2}{|c|}{ All Stages } & \multicolumn{2}{|c|}{ Stages 2-3 } \\
\hline & Coeff. & Std. Err. & Coeff. & Std. Err. \\
\hline WeakEnforcement & $8.82 * * *$ & $(2.63)$ & $15.97 * * *$ & $(3.02)$ \\
\hline StrongEnforcement & -1.10 & $(2.64)$ & 3.17 & $(3.05)$ \\
\hline Period & $3.35 * * *$ & $(1.22)$ & $4.74 * * *$ & $(1.42)$ \\
\hline Period $^{2}$ & $-0.40 * *$ & $(0.17)$ & $-0.58 * * *$ & $(0.20)$ \\
\hline WeakEnforcement $\times$ Period & -1.75 & (1.69) & $-5.46 * * *$ & $(1.92)$ \\
\hline WeakEnforcement $\times$ Period $^{2}$ & 0.16 & $(0.24)$ & $0.63 * *$ & $(0.27)$ \\
\hline StrongEnforcement $\times$ Period & 1.54 & $(1.69)$ & -1.08 & $(1.95)$ \\
\hline StrongEnforcement $\times$ Period $^{2}$ & -0.23 & $(0.24)$ & 0.08 & $(0.27)$ \\
\hline Session 1 & 0.04 & $(0.97)$ & 0.01 & $(1.16)$ \\
\hline WeakEnforcement $\times$ Session 1 & -1.38 & $(1.39)$ & -2.48 & $(1.61)$ \\
\hline StrongEnforcement $\times$ Session 1 & -0.05 & $(1.36)$ & -0.03 & $(1.65)$ \\
\hline Constant & $36.28 * * *$ & (1.91) & $34.14^{* * *}$ & $(2.23)$ \\
\hline Observations & 438 & & 300 & \\
\hline Number of Unique Groups & 26 & & 26 & \\
\hline
\end{tabular}

Standard errors in parentheses: $* * * p<0.01$, ** $p<0.05$, $* p<0.1$. 
Table 7. Linear random effects model of aggregate permits banked

\begin{tabular}{lcccc}
\hline \multirow{2}{*}{ VARIABLES } & \multicolumn{2}{c}{ All Stages } & \multicolumn{2}{c}{ Stages 2-3 } \\
\cline { 2 - 5 } WeakEnforcement & Coeff. & Std. Err. & Coeff. & Std. Err. \\
StrongEnforcement & $10.20^{* * *}$ & $(3.15)$ & $9.38^{* * *}$ & $(3.51)$ \\
Periods1-3 & 4.80 & $(3.15)$ & 4.04 & $(3.53)$ \\
Periods4-6 & $25.71^{* * *}$ & $(0.78)$ & $25.42^{* * *}$ & $(0.88)$ \\
WeakEnforcement $\times$ Periods $1-3$ & $-26.92^{* * *}$ & $(0.51)$ & $-27.18^{* * *}$ & $(0.58)$ \\
WeakEnforcement $\times$ Periods4-6 & 0.66 & $(0.71)$ & 1.17 & $(0.79)$ \\
StrongEnforcement $\times$ Periods $1-3$ & $-1.95^{*}$ & $(1.08)$ & -1.76 & $(1.20)$ \\
StrongEnforcement $\times$ Periods4-6 & 0.53 & $(0.71)$ & 1.27 & $(0.80)$ \\
Session 1 & $6.76^{* * *}$ & $(2.50)$ & $7.53^{* * *}$ & $(2.82)$ \\
WeakEnforcement $\times$ Session1 & $-15.95^{* * *}$ & $(3.51)$ & $-18.58^{* * *}$ & $(3.92)$ \\
StrongEnforcement $\times$ Session1 & -1.94 & $(3.49)$ & -5.13 & $(3.95)$ \\
Constant & 0.89 & $(2.30)$ & 1.59 & $(2.60)$ \\
& & & & \\
Observations & 438 & & 300 & \\
Number of Unique Groups & 26 & & 26 & \\
\hline
\end{tabular}

Standard errors in parentheses: $* * * p<0.01$, ** $p<0.05, * p<0.1$. 
Table 8. Linear random effects model of permit prices

\begin{tabular}{|c|c|c|c|c|}
\hline \multirow[b]{2}{*}{ VARIABLES } & \multicolumn{2}{|c|}{ All Stages } & \multicolumn{2}{|c|}{ Stages 2-3 } \\
\hline & Coeff. & Std. Err. & Coeff. & Std. Err. \\
\hline WeakEnforcement & $-4.90 * *$ & (2.45) & $-12.92 * * *$ & $(2.32)$ \\
\hline StrongEnforcement & 1.94 & (2.46) & $-7.32^{* * *}$ & (2.34) \\
\hline Period & $-6.68 * * *$ & $(0.65)$ & $-8.39 * * *$ & $(0.62)$ \\
\hline Period $^{2}$ & $0.73^{* * *}$ & $(0.10)$ & $1.04^{* * *}$ & $(0.10)$ \\
\hline WeakEnforcement $\times$ Period & -1.29 & $(0.86)$ & $4.14^{* * *}$ & $(0.81)$ \\
\hline WeakEnforcement $\times$ Period $^{2}$ & $0.37^{* * *}$ & $(0.13)$ & $-0.42 * * *$ & $(0.12)$ \\
\hline StrongEnforcement $\times$ Period & $-2.10 * *$ & $(0.89)$ & $4.90^{* * *}$ & $(0.84)$ \\
\hline StrongEnforcement $\times$ Period $^{2}$ & $0.33^{* *}$ & $(0.14)$ & $-0.60 * * *$ & $(0.13)$ \\
\hline Session1 & $6.69 * *$ & (2.62) & $4.64 *$ & $(2.50)$ \\
\hline WeakEnforcement $\times$ Session 1 & $-11.92 * * *$ & (3.65) & $-6.07 *$ & (3.47) \\
\hline StrongEnforcement $\times$ Session 1 & -5.81 & (3.65) & $-8.07 * *$ & $(3.48)$ \\
\hline Constant & $88.32 * * *$ & $(1.81)$ & $89.57 * * *$ & $(1.73)$ \\
\hline Observations & 6879 & & 4771 & \\
\hline Number of Unique Groups & 26 & & 26 & \\
\hline
\end{tabular}

Standard errors in parentheses: ${ }^{* * *} p<0.01,{ }^{* *} p<0.05,{ }^{*} p<0.1$. 
Table 9. Linear random effects estimation of individual production by stage

\begin{tabular}{|c|c|c|c|c|c|c|}
\hline \multirow[b]{2}{*}{ VARIABLES } & \multicolumn{2}{|l|}{ Stage 1} & \multirow{2}{*}{$\begin{array}{c}\text { Stage } 2 \\
\text { Coeff. }\end{array}$} & \multicolumn{3}{|c|}{ Stage 3} \\
\hline & Coeff. & Std.Err. & & Std.Err. & Coeff. & Std.Err. \\
\hline Average Price & $-0.04 * * *$ & $(0.00)$ & $-0.07 * * *$ & $(0.01)$ & $-0.07 * * *$ & $(0.01)$ \\
\hline WeakEnforcement & 0.31 & $(0.64)$ & $1.59^{* * *}$ & $(0.54)$ & $1.74 * * *$ & $(0.50)$ \\
\hline SubjectTyреB & 0.52 & $(0.44)$ & $1.10^{* *}$ & $(0.43)$ & $0.83^{* *}$ & $(0.37)$ \\
\hline SubjectTypeC & -0.47 & $(0.44)$ & $-1.08 * *$ & $(0.43)$ & $-1.45^{* * *}$ & $(0.37)$ \\
\hline SubjectTypeD & $-0.80 *$ & $(0.44)$ & $-1.73^{* * *}$ & $(0.43)$ & $-2.19 * * *$ & $(0.37)$ \\
\hline Period & 0.10 & $(0.22)$ & 0.07 & $(0.16)$ & $0.30 *$ & $(0.16)$ \\
\hline Period $^{2}$ & -0.02 & $(0.03)$ & -0.01 & $(0.02)$ & $-0.05^{* *}$ & $(0.02)$ \\
\hline WeakEnforcement $\times$ SubjectTypeB & -0.56 & $(0.64)$ & $-1.87 * * *$ & $(0.59)$ & $-1.53^{* * *}$ & $(0.53)$ \\
\hline WeakEnforcement $\times$ SubjectTypeC & $-1.32 * *$ & $(0.64)$ & $-1.05^{*}$ & $(0.59)$ & -0.77 & $(0.53)$ \\
\hline WeakEnforcement $\times$ SubjectTypeD & -0.69 & $(0.64)$ & -0.14 & $(0.59)$ & -0.01 & $(0.53)$ \\
\hline WeakEnforcement $\times$ Period & 0.17 & $(0.30)$ & $-0.44 * *$ & $(0.22)$ & $-0.52 * *$ & $(0.22)$ \\
\hline WeakEnforcement $\times$ Period $^{2}$ & -0.02 & $(0.04)$ & $0.06^{*}$ & $(0.03)$ & $0.07 * *$ & $(0.03)$ \\
\hline ForcedCompliance & 0.92 & $(0.61)$ & 0.53 & $(0.57)$ & $0.91^{*}$ & $(0.51)$ \\
\hline ForcedCompliance $\times$ SubjectTypeB & -0.34 & $(0.62)$ & -0.70 & $(0.63)$ & -0.89 & $(0.55)$ \\
\hline ForcedCompliance $\times$ SubjectTypeC & -0.34 & $(0.62)$ & -0.68 & $(0.63)$ & -0.63 & $(0.55)$ \\
\hline ForcedCompliance $\times$ SubjectTypeD & -0.81 & $(0.62)$ & -0.69 & $(0.63)$ & -0.66 & $(0.55)$ \\
\hline ForcedCompliance $\times$ Period & -0.29 & $(0.29)$ & -0.09 & $(0.24)$ & -0.20 & $(0.23)$ \\
\hline ForcedCompliance $\times$ Period $^{2}$ & 0.03 & $(0.04)$ & 0.02 & $(0.03)$ & 0.03 & $(0.03)$ \\
\hline Constant & $8.90^{* * *}$ & $(0.67)$ & $11.30^{* * *}$ & $(0.58)$ & $11.01^{* * *}$ & $(0.64)$ \\
\hline Observations & 1096 & & 1152 & & 1248 & \\
\hline Number of Unique Subjects & 184 & & 192 & & 208 & \\
\hline
\end{tabular}

Standard errors in parentheses: ${ }^{* * *} p<0.01,{ }^{* *} p<0.05,{ }^{*} p<0.1$. 
Table 10. Random effects logit estimation of the individual probability of reporting violation

\begin{tabular}{|c|c|c|c|c|c|c|}
\hline \multirow[b]{2}{*}{ VARIABLES } & \multicolumn{2}{|l|}{ Stage 1} & \multicolumn{2}{|l|}{ Stage 2} & \multicolumn{2}{|l|}{ Stage 3} \\
\hline & Coeff. & Std. Err. & Coeff. & Std. Err. & Coeff. & Std. Err. \\
\hline Average Price & 0.00 & $(0.01)$ & $0.04 * *$ & $(0.02)$ & 0.03 & $(0.03)$ \\
\hline WeakEnforcement & $3.50 * *$ & $(1.68)$ & $4.37 * *$ & $(1.75)$ & $6.19 * * *$ & $(1.82)$ \\
\hline SubjectTyреB & 0.61 & $(1.13)$ & 2.20 & $(1.44)$ & 0.62 & $(1.44)$ \\
\hline SubjectTypeC & 0.16 & $(1.16)$ & 2.12 & $(1.44)$ & 0.79 & $(1.42)$ \\
\hline SubjectTypeD & -0.35 & $(1.21)$ & 2.06 & $(1.44)$ & 0.32 & $(1.46)$ \\
\hline Period & 0.36 & $(0.72)$ & -0.29 & $(0.61)$ & 0.62 & $(0.67)$ \\
\hline Period $^{2}$ & -0.04 & $(0.10)$ & 0.02 & $(0.09)$ & -0.10 & $(0.10)$ \\
\hline WeakEnforcement $x$ SubjectTypeB & -0.63 & $(1.54)$ & -2.35 & $(1.75)$ & -1.78 & $(1.81)$ \\
\hline WeakEnforcement $\times$ SubjectTypeC & -0.62 & $(1.56)$ & -2.64 & $(1.75)$ & -1.70 & (1.79) \\
\hline WeakEnforcement $\times$ SubjectTypeD & 1.20 & (1.58) & -2.16 & (1.73) & -0.43 & $(1.81)$ \\
\hline WeakEnforcement $\times$ Period & -0.93 & $(0.81)$ & 0.19 & $(0.75)$ & -0.95 & $(0.80)$ \\
\hline WeakEnforcement $\times$ Period $^{2}$ & 0.10 & $(0.11)$ & -0.07 & $(0.11)$ & 0.09 & $(0.11)$ \\
\hline Constant & $-4.64^{* *}$ & $(2.17)$ & $-8.41^{* * *}$ & $(2.26)$ & $-7.86^{* * *}$ & (2.68) \\
\hline Observations & 712 & & 816 & & 864 & \\
\hline Number of Unique Subjects & 120 & & 136 & & 144 & \\
\hline
\end{tabular}

Standard errors in parentheses: ${ }^{* * *} p<0.01,{ }^{* *} p<0.05$, ${ }^{*} p<0.1$. 
Figure 1. Mean aggregate production in stages 2-3 for sessions 2-3.

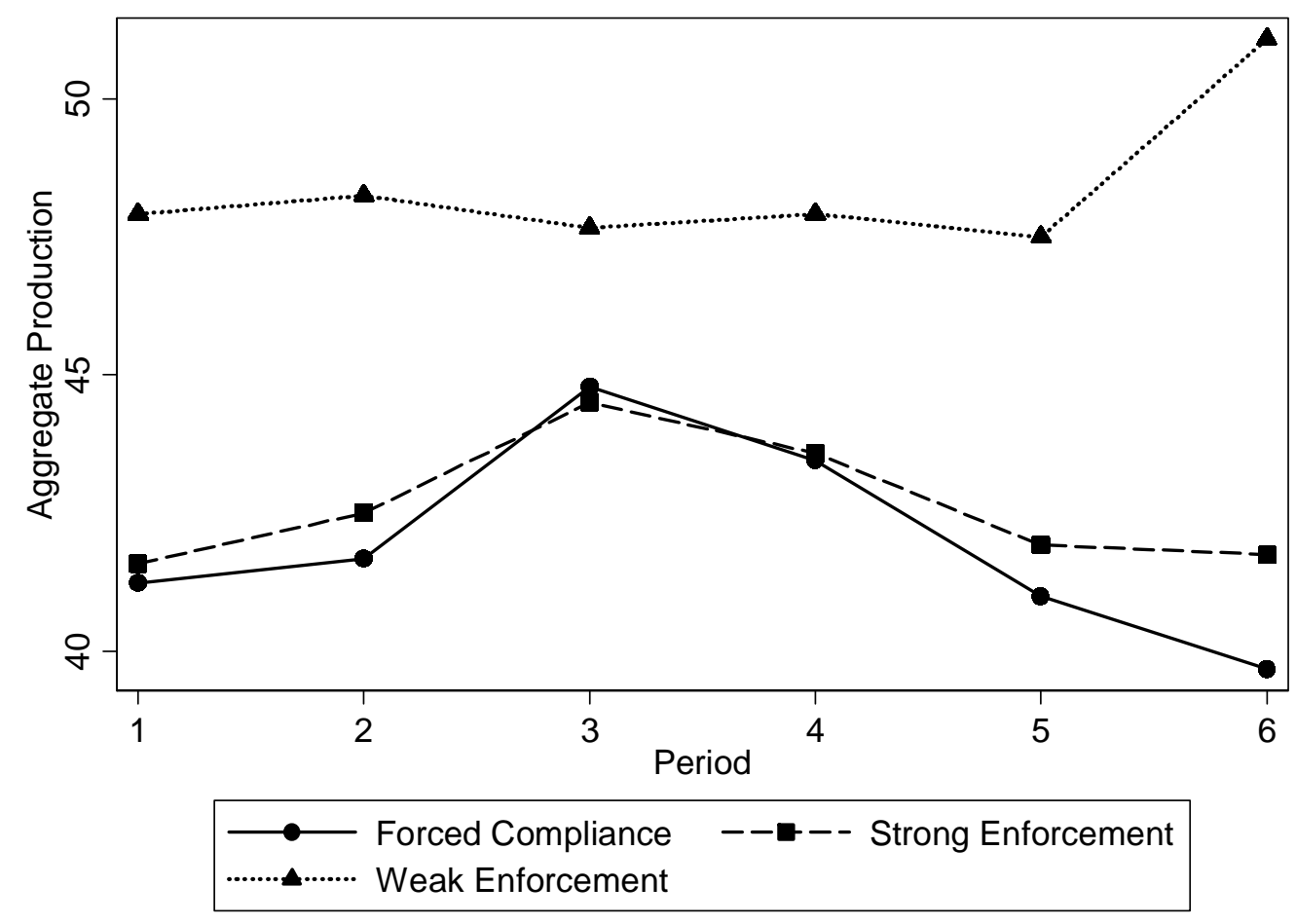


Figure 2. Mean aggregate number of permits banked in stages 2-3 for sessions 2-3.

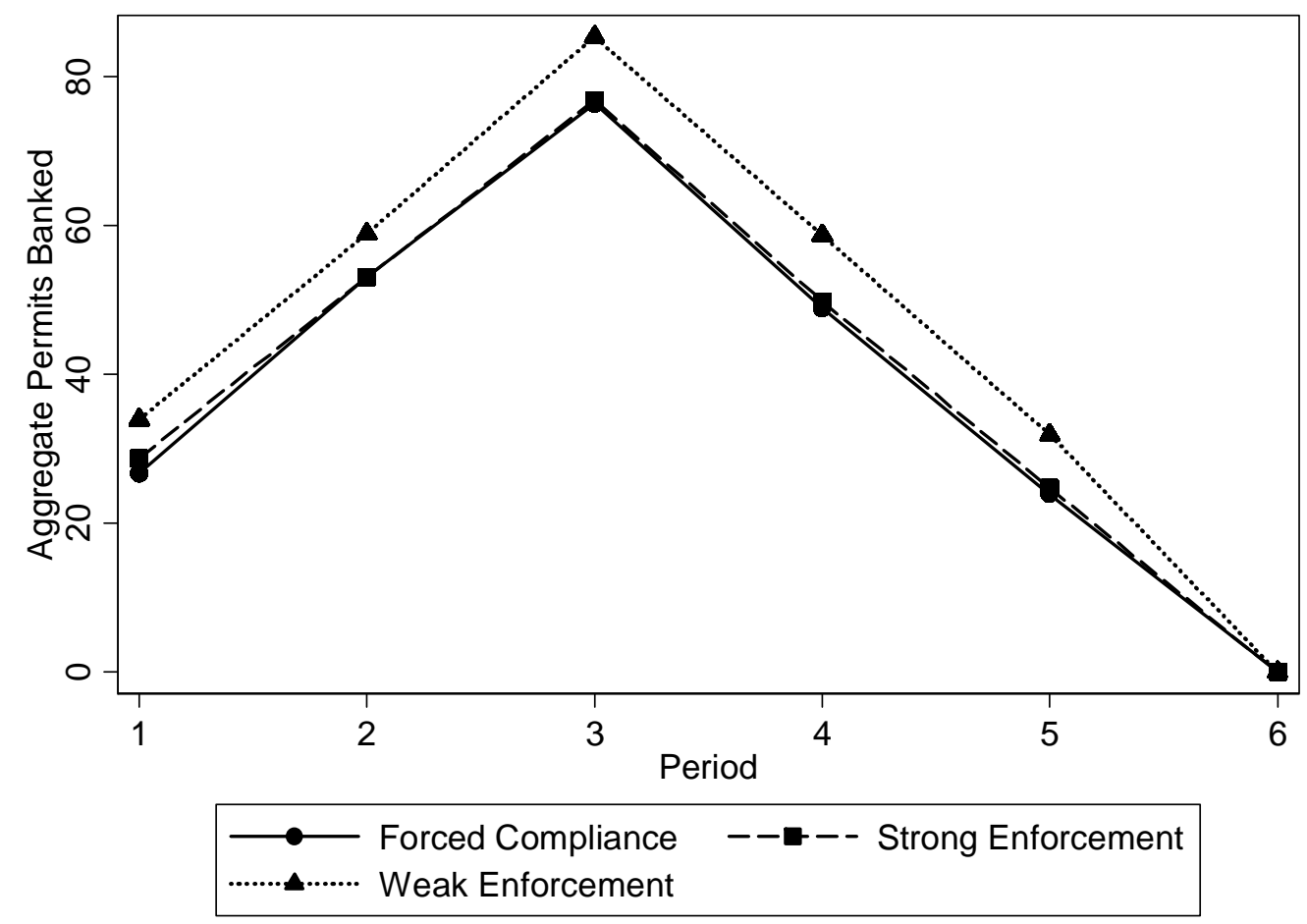


Figure 3. Mean permit prices in stages 2-3 for sessions 2-3

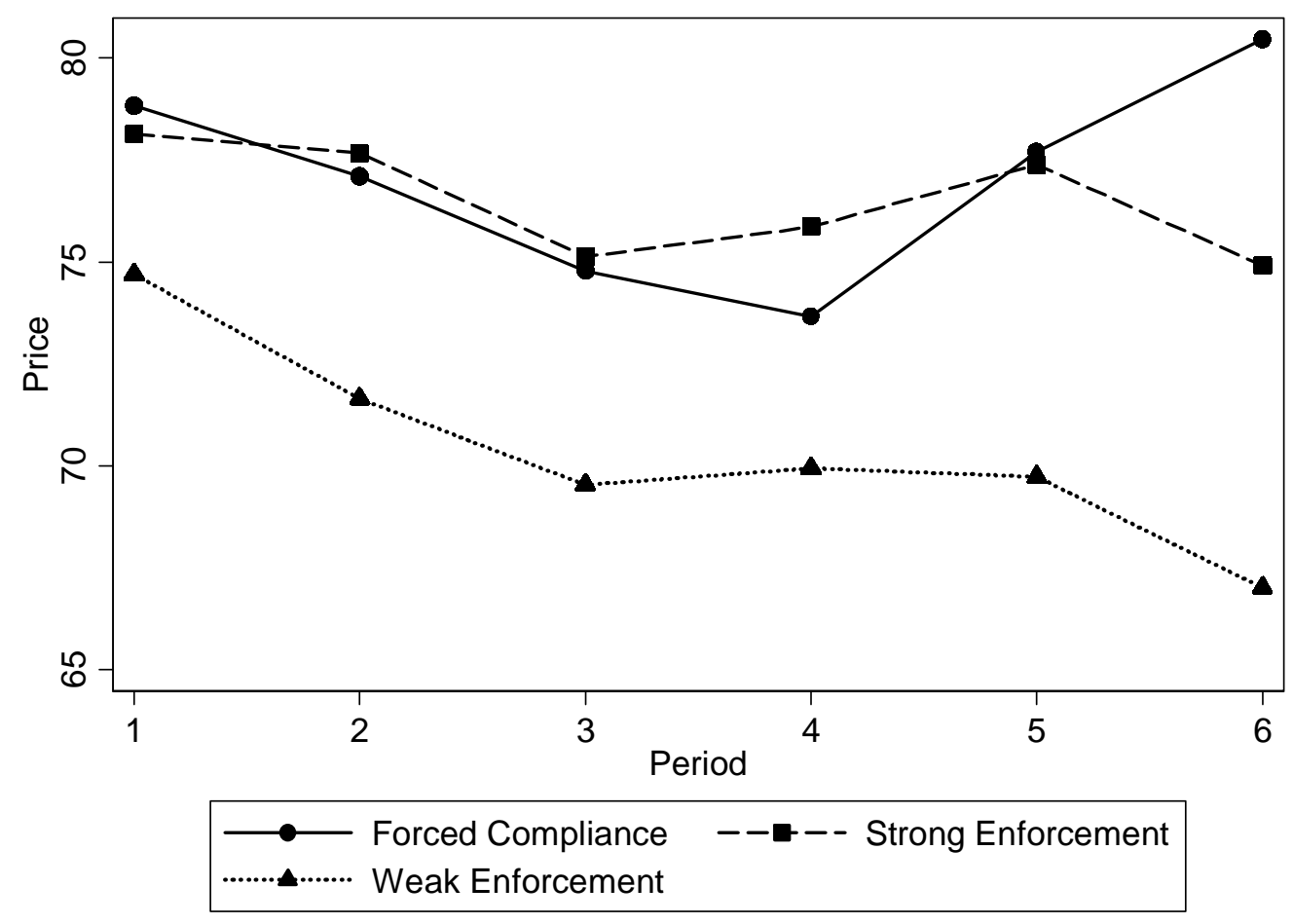




\section{References}

Anderson Christopher, M. and Jon G. Sutinen. 2006. “The Effect of Initial Lease Periods on Price Discovery in Laboratory Tradable Fishing Allowance Markets.” Journal of Economics Behavior and Organization 61(2), 164-180.

Cason, Timothy N. and Lata Gangadharan. 2006. "Emissions Variability in Tradable Permit Markets with Imperfect Enforcement and Banking.” Journal of Economic Behavior and Organization 61(2), 199-216.

Chavez, Carlos A. and John K. Stranlund. 2003. "Enforcing Transferable Permit Systems in the Presence of Market Power.” Environmental and Resource Economics 25(1), 65-78.

Cronshaw, Mark and Jamie Brown Kruse. 1996. "Regulated Firms in Pollution Permit Markets With Banking.” Journal of Regulatory Economics 9, 179-189.

Ellerman, A. D. and P. L. Joskow. 2008. The European Union's Emissions Trading System in Perspective. Pew Center on Global Climate Change.

Godby, Robert W., Stuart, Mestelman, R. Andrew Muller, and J. Douglas Welland. 1997. "Emissions Trading with Shares and Coupons when Control over Discharges is Uncertain." Journal of Environmental Economics and Management 32(3), 359-381.

Innes, Robert. 1999. "Remediation and Self-Reporting in Optimal Law Enforcement.” Journal of Public Economics 72, 379-393.

Innes, Robert. 2000. "Self-Reporting in Optimal Law Enforcement When Violators Have Heterogeneous Probabilities of Apprehension.” Journal of Legal Studies 29, 287-300.

Innes, Robert. 2001. "Violator Avoidance Activities and Self-Reporting in Optimal Law Enforcement.” Journal of Law, Economics, and Organization 17(1), 239-256.

Innes, Robert. 2003. "Stochastic Pollution, Costly Sanctions, and Optimality of Emission Permit Banking.” Journal of Environmental Economics and Management 45(3), 546-68.

Kaplow, Louis and Steven Shavell. 1994. “Optimal Law Enforcement with Self-Reporting of Behavior.” Journal of Political Economy 103(3), 583-606.

Keeler, Andrew 1991. "Noncompliant Firms in Transferable Discharge Permit Markets: Some Extensions.” Journal of Environmental Economics and Management 21(2), 180-189.

Kling, Catherine and Jonathan Rubin. 1997. "Bankable Permits for the Control of Environmental Pollution.” Journal of Public Economics 64, 101-115.

Livernois, John and C.J. McKenna. 1999. "Truth or Consequences: Enforcing Pollution Standards with Self-Reporting.” Journal of Public Economics 73(3), 415-440.

Malik, Arun S. 1990. “Markets for Pollution Control when Firms are Noncompliant.” Journal of Environmental Economics and Management 18(2), 97-106.

Malik, Arun. S. 1992. “Enforcement Cost and the Choice of Policy Instruments for Controlling Pollution.” Economic Inquiry 30(4), 714-721.

Malik, Arun. 1993. "Self-Reporting and the Design of Policies for Regulating Stochastic Pollution.” Journal of Environmental Economics and Management 24, 241-257. 
Malik, Arun. 2002. "Further Results on Permit Markets with Market Power and Cheating." Journal of Environmental Economics and Management 44(3), 371-390.

Muller, R. Andrew and Stuart Mestelman. 1998. "What Have we Learned From Emission Trading Experiments?” Managerial and Decision Economics 19, 225-238.

Murphy, James J. and John K. Stranlund. 2006. "Direct and Indirect Effects of Enforcing Emissions Trading Programs: An Experimental Analysis.” Journal of Economic Behavior and Organization 61(2), 217-233.

Murphy, James J. and John K. Stranlund. 2007. “A Laboratory Investigation of Compliance Behavior under Tradable Emissions Rights: Implications for Targeted Enforcement.” Journal of Environmental Economics and Management 53(2), 196-212.

Rubin, Jonathan. 1996. “A Model of Intertemporal Emissions Trading, Banking, and Borrowing.” Journal of Environmental Economics and Management 31, 269-286.

Schennach, Susanne. 2000. "The Economics of Pollution Permit Banking in the Context of Title IV of the 1990 Clean Air Act Amendments.” Journal of Environmental Economics and Management 40(3): 189-210.

Stranlund, John K. and Kathy K. Dhanda. 1999. "Endogenous Monitoring and Enforcement of a Transferable Emissions Permit System.” Journal of Environmental Economics and Management 38(3), 267-282.

Stranlund, John K. 2007. "The Regulatory Choice of Noncompliance in Emissions Trading Programs.” Environmental and Resource Economics 38(1), 99-117.

Stranlund, John K., Christopher Costello, and Carlos A. Chavez. 2005. "Enforcing Emissions Trading when Emissions Permits are Bankable.” Journal of Regulatory Economics 28(2), 181-204.

Stranlund, John K. and Carlos Chavez. 2000. "Effective Enforcement of a Transferable Emissions Permit System with a Self-Reporting Requirement.” Journal of Regulatory Economics 18(2), 113-131.

Stranlund, John K. and Kanwalroop K. Dhanda. 1999. "Endogenous Monitoring and Enforcement of a Transferable Emissions Permit System.” Journal of Environmental Economics and Management 38(3), 267-282.

Tietenberg, Tom H., 2006. Emissions Trading: Principles and Practice, $2^{\text {nd }}$ Edition. Resources for the Future. Washington DC.

vanEgteren, Henry and Marian Weber. 1996. "Marketable Permits, Market Power, and Cheating.” Journal of Environmental Economics and Management 30, 161-173. 